\title{
Effects of Egg Shell Membrane Hydrolysates on UVB-radiation-induced Wrinkle Formation in SKH-1 Hairless Mice
}

\author{
Jin Hee Yoo, Jong Keun Kim¹, Hee Jin Yang ${ }^{1}$, and Ki Moon Park* \\ Department of Food Science and Biotechnology, Sungkyunkwan University, Suwon 440-746, Korea \\ ${ }^{1}$ SungKyun Biotech Co., LTD R\&D center, Ansan \#1123, Korea
}

\begin{abstract}
This study was conducted to examine the effect of egg shell membrane hydrolysates (ESMH) on wrinkle, UV, and moisture protection for cosmetic use. ESMH were fragmented as whole ESMH (before fractioning), Fraction I ( $>10 \mathrm{kDa})$, Fraction II $(3-10 \mathrm{kDa})$, and Fraction III $(<3 \mathrm{kDa})$. In order to test whether fractionated ESMH can be used for functional cosmetic materials, we examined not only the level of hyaluronic acid and collagen production, but also the MMP-1 activity using a HaCaT and CCD-986Sk cell line. Our study treated each sample of fractionated ESMH with different concentrations $(0.01,0.1,1 \mathrm{mg} / \mathrm{mL})$. In our in vivo research, we used hairless mice that had been exposed to UV-B to induce wrinkles for $7 \mathrm{wk}$, then applied Fraction I to the treatment group for $5 \mathrm{wk}$ and then tested skin thickness, minimum erythema dose and moisture content. In addition, Fraction I was high in collagen and HA biosynthesis and it was better than TGF- $\beta$ in improving of the skin. When TNF- $\alpha$ caused MMP-1 activity in the CCD-986Sk cells, the whole ESMH and Fraction I proved to be effective in hindering the induction of collagenase depending on the concentration, and also showed outstanding effects in the suppression of skin aging. We found that the treatment group mice's UV-B radiation-induced skin damage was largely mitigated compared to that of the non-treatment group mice. Thus, we have concluded that EMSH helps to mitigate UV-B radiation-induced wrinkles, collagen, HA, MMP-1 activity and can be used for functional cosmetic materials.
\end{abstract}

Key words: egg shell membrane, anti-aging, moisture protection, MMP-1, 2, 9, collagen

\section{Introduction}

Skin is essential for human survival. Depending on the environment, it functions as a barrier, temperature control, and helps the body skin to maintain internal homeostasis. But the state of human skin is affected by outside circumstances like ultraviolet (UV) rays, inflammation etc., and inner factors like aging and mental stress; and as a result, it's ordinary function can deteriorate. In particular, UV rays lead to wrinkles, loss of elasticity, and pigmentation of skin. In the case of a decrease in skin moisture content through damage to the skin barrier, the skin surface gets rough. In order to keep it fresh, it is important to maintain skin moisture content and elasticity (Bae et al., 2009; Candilish and Scougall, 1969; Chisato et al., 2013; Cho, 2007; Chung, 2003). Accordingly, people rely on cosmetics for beauty and skin care. Currently, due to

\footnotetext{
*Corresponding author: Kimoon Park, Department of Food Science and Biotechnology, Sungkyunkwan University, Suwon 440-746, Korea. Tel: +82-31-290-7806, Fax: +82-31-290-7810, E-mail: pkm1001@skku.edu
}

the development of this industry, interest in 'functional' cosmetics extends beyond simple beauty uses.

Studies have been conducted on ways to increase skin moisturization (Cong et al., 2008; Fisher et al., 1996), to better protect the skin from the UV radiation in sunlight (Cong et al., 2008; Fisher et al., 1996), to increase the recovery rate of the skin from UV radiation damage (Cong et al., 2008; Gloster and Neal, 2006), and to increase blood circulation and skin cell proliferation (Cong et al., 2008; Gonzaga, 2009). Retinoic acid and epigallocatechin gallate (EGCG) are known to prevent collagen from being broken down under the influence of denatured MMP proteins and elastase, which is a consequence of UV light exposure, and from skin aging caused by the accumulation of denatured collagen. Such compounds have been used in increasing cell activity, moisture protection and collagen storage (Cong et al., 2008; Green, 1991). Collagen has been used as a cosmetic ingredient due to its effect in enhancing skin firmness and moisturization.

Recently, research has been performed that verifies its effects on joints and bones (Haratake et al., 1998; Held et al., 1999; Iwai et al., 2005). 
A study is also underway that aims to determine the extent to which collagen is absorbed into the human body, and its effects (Jenkins, 2002; Jiang et al., 2007). Currently, commercial products use collagen extracts from swine flesh and fish, and have low polymer molecular weights with molecule sizes of $30 \mathrm{kDa}$ or $1-5 \mathrm{kDa}$. Further development and investigation into natural products are expected to lead to domestic and overseas cosmetics materials development.

Above all, there is consumer demand for cosmetic products that contain natural ingredients, which has resulted in the development of functional cosmetic products that have moisture and skin recovery properties to counter aging (Kang, 1997).

Egg shell membrane (ESM) is an organic substance that has been shown to increase cellular activity and collagen production. Furthermore, ESM prevents skin aging and reduces damage caused by UV light and inflammation (Karna et al., 2011). ESM is made of insoluble protein keratin, which is also present in feathers, hair, horns, scales, and nails. Keratin is very resistant to physical, chemical, and biological reactions (Kim et al., 2009). ESM has been suggested for use in formulations for moisturizers, wound recovery, skin growth, anti-wrinkle agents, whitening, and anti-microbial activity (Cong et al., 2008; Kim, 2009; Lee, 2010).

We have demonstrated in a previous study that whole egg shell membrane hydrolysates (ESMH) had a skin whitening effect due to their tyrosinase inhibiting and LDOPA oxidizing activities. Furthermore, we confirmed the wound healing effects of ESMH using a human keratinocyte cell line (HaCaT) (Cong et al., 2008). In addition, we showed in a previous study that ESMH proved to be effective in hindering the induction of cell inflammation depending on concentration, and also showed outstanding effects in suppressing skin inflammation. In experiments with collagenase and elastase inactivity, the fraction $(>10 \mathrm{kDa})$ showed a hindrance rate higher than other fractions, and all the fractions were observed to have antibiotic effects. In addition, we showed moisture protection effects in terms of moisture retention with a relatively low moisture loss rate in the skin, which enabled us to confirm that the hydrolyzed fractions of ESM form a superior protective layer of moisture (Lee et al., 2008). In this study, we conducted hydrolysis of ESM, and classified the results into three categories of molecular weight (ESMH Fractions I (>10 kDa), Fraction II (3$10 \mathrm{kDa})$, and Fraction III ( $<3 \mathrm{kDa})$, and finally confirmed a variety of physiological activities, such as collagen syn- thesis, matrix metalloproteinase-I activity, and moisture protection. We also used hairless mice that were exposed to UV-B to induce wrinkles for $7 \mathrm{wk}$. We then applied ESMH Fraction I to the treatment group for $5 \mathrm{wk}$ and then tested skin thickness, minimum erythema dose and moisture content.

\section{Materials and Methods}

\section{Egg shell membrane hydrolysates}

The ESM used in this study was provided by Sungkyun Biotech Co., Ltd. First, $100 \mathrm{~g}$ of dried ESM were added to $1100 \mathrm{~mL}$ of distilled water, $2 \mathrm{~N} \mathrm{NaOH}$ and $40 \% \mathrm{EtOH}$ before being kept at $70^{\circ} \mathrm{C}$ for $2 \mathrm{~h}$ for the reactions. After the reactions, $99 \%$ acetic acid was added for neutralization ( $\mathrm{pH} 7.0)$ and $40 \mathrm{~g}$ of activated carbon was added for decolorization for $20 \mathrm{~min}$. The extract was filtered through a Whatman No.1 filter paper and desalinated using a Micro Acilyzer G3 (Asashi Kasei Corp., Japan). It was then evaporated and freeze-dried (FD 3, Heto, Gydevang, Denmark). Then, the ESMs was divided into three fragments: Fraction I ( $>10 \mathrm{kDa})$, Fraction II (3-10 kDa), and Fraction III ( $<3 \mathrm{kDa})$ as described previously (Park et al., 2012).

\section{Cell culture}

The CCD-986Sk cells derived from human skin fibroblasts (Korean Cell Line Bank; KCLB), were cultivated in Dulbecco's Modified Eagle's Medium (DMEM) with $10 \%$ fetal bovine serum (FBS) at $37^{\circ} \mathrm{C}$ in a $95 \%$ air, $5 \%$ $\mathrm{CO}_{2}$ atmosphere. When cells filled $90 \%$ of the culture dish, it was centrifuged at 2,000 rpm for $3 \mathrm{~min}$, and then collected for dilution in a 1:5 ratio. HaCaT cells from the human keratinocyte cell line were supplied by the Dermatological Sciences Research Center of Chung-Ang University, Korea. For the HaCaT cells, a DMEM medium with a $10 \%$ FBS and $1 \%$ penicillin-streptomycin was used. When cells filled $90 \%$ of the culture dish, it was centrifuged at 2,000 rpm for $3 \mathrm{~min}$, and then collected for dilution in a 1:5 ratio.

\section{Collagen synthesis (UV-B)}

CCD-986Sk cells were added to a 48-well plate at a concentration of $5 \times 10^{4}$ cells $/ \mathrm{ml}$ and then left in a $5 \% \mathrm{CO}_{2}$ incubator at $37^{\circ} \mathrm{C}$. After $24 \mathrm{~h}$, the medium was drained and cells were irradiated with a UV-B lamp with $20 \mathrm{~mJ} /$ $\mathrm{cm}^{2}$. Then cells were grown in culture dishes with the addition of different concentrations of ESMH (whole ESMH, Fractions I, II, and III). At the indicated time, aliquots of 
medium were removed, centrifuged at $15,000 \mathrm{~g}$ for $5 \mathrm{~min}$, and supernatants were analyzed for pro-collagen type I Cpeptide ELISA kit (Takara Bio Inc., Japan). TGF- $\beta$ (10 $\mathrm{ng} / \mathrm{mL}$ ) was used as a positive control.

\section{Matrix metalloproteinase-I activity (UV-B)}

CCD-986Sk cells were added to a 48-well plate at a concentration of $5 \times 10^{4}$ cells $/ \mathrm{ml}$ and then left in a $5 \% \mathrm{CO}_{2}$ incubator at $37^{\circ} \mathrm{C}$. After $24 \mathrm{~h}$, the medium was drained and cells were irradiated with a UV-B lamp with $20 \mathrm{~mJ} /$ $\mathrm{cm}^{2}$. Then cells were grown in culture dishes with the addition of different concentrations of ESMH (whole ESMH, Fractions I, II, and III). At this time, TNF- $\beta$ was added at a concentration of $10 \mathrm{ng} / \mathrm{ml}$ in order to enhance the activity of MMP-1. At the indicated time, aliquots of medium were removed, centrifuged at $15,000 \mathrm{~g}$ for $5 \mathrm{~min}$, and supernatants were analyzed with the Matrix Metalloproteinase-1 Biotrack Activity Assay Kit (Amersham Bioscience). Ascorbic acid $(0.2 \mathrm{mM})$ was used as a positive control.

\section{Hyaluronan (HA) production}

$\mathrm{HaCaT}$ cells were grown to high density in 24-well plates $\left(2 \times 10^{5}\right.$ cells $\left./ \mathrm{mL}\right)$. Immediately before experiments, cells were washed two times with serum-free medium to completely remove HA accumulated during cell growth. Subsequently, $\mathrm{HaCaT}$ cells were cultured with or without ESMH in $0.5 \mathrm{~mL}$ serum-free medium for $24 \mathrm{~h}$. At the indicated time, aliquots of medium were removed, centrifuged at $15,000 \mathrm{~g}$ for $5 \mathrm{~min}$, and supernatants were analyzed for HA using an enzyme-linked immunosorbent assay (ELISA) kit (Echelon Bioscience, US).

\section{UV irradiation and Real-time RT-PCR analysis}

After UV-B irradiation $\left(20 \mathrm{~mJ} / \mathrm{cm}^{2}\right)$ with or without subsequent ESMH (whole ESMH, Fractions I, II, and III) treatment, the expression of COX-2, MMP-2 and MMP-9 in cultured CCD-986Sk cells $\left(2 \times 10^{6}\right.$ cells $\left./ \mathrm{mL}\right)$ was examined using real-time RT-PCR and was normalized against glyceraldehyde-3-phosphate dehydrogenase (GAPDH). The RNA was extracted using TRIzol reagent (Invitrogen Co., CAT. 15596-026) and Easy-Spin TM Total RNA Extraction Kit (Intron Bio technology, Korea, CAT. 17221) and stored at $-70^{\circ} \mathrm{C}$ until before the experiment. To measure the RNA template concentration, a spectrophotometer was used; $1 \mu \mathrm{g}$ of total RNA template was mixed with 300 pmol random primer and ultrapure water (Invitrogen, USA) was added to form $10 \mu \mathrm{l}$ of total volume, which was heated at $65^{\circ} \mathrm{C}$ for $5 \mathrm{~min}$. To synthesize cDNA, $4 \mu \mathrm{L}$ 5X RTase M-MLV buffer, $10 \mathrm{mM}$ dNTP Mixture, RTase M-MLV (Takara, 2640A, Japan) and ultra-pure water (a total volume of $20 \mu \mathrm{L}$ ) was incubated at $37^{\circ} \mathrm{C}$ for $50 \mathrm{~min}$ and heated at $70^{\circ} \mathrm{C}$ for $10 \mathrm{~min}$; the cDNA was analyzed by Thermal Cycler Dice (Takara, TP800, Japan) using the power SYBR premix Ex Taq (Takara, RP041A, Japan) and specific oligonucleotide primers as follows (Table 1).

\section{Animal experiments}

Female SKH-1 hairless mice were obtained from Charles River Laboratory (Orient Co. LTD, Korea). These animals were maintained at $23 \pm 3^{\circ} \mathrm{C}$ with $50 \pm 10 \%$ relative humidity and a $12 \mathrm{~h}$ light: $12 \mathrm{~h}$ dark cycle. $\mathrm{SKH}-$

Table 1. Primer sequences used in this study

\begin{tabular}{|c|c|c|c|}
\hline Primer & Sequence & $\overline{\text { Size (bp) }}$ & $\bar{T} \operatorname{Tm}\left({ }^{\circ} \mathrm{C}\right)$ \\
\hline GAPDH & $\begin{array}{l}\text { Forward: 5'-GAAGGTGAAGGTCGGAGTCAACG-3' } \\
\text { Reverse: 5'-AGTCCTTCCACGATAACCAAAGTTG-3' }\end{array}$ & 384 & 59 \\
\hline COL1A1 & $\begin{array}{l}\text { Forward: 5'-GGCGGCCAGGGCTCCGACCC-3' } \\
\text { Reverse: 5'-ATTCCTGGTCTGGGGCACC -3' }\end{array}$ & 346 & 59 \\
\hline COX-2 & $\begin{array}{l}\text { Forward: 5'-TTCAAATGAGATTGTGGGAAAAT-3' } \\
\text { Reverse: 5'-AGATCATCTCTGCCTGAGTATCTT-3' }\end{array}$ & 305 & 59 \\
\hline MMP-2 & $\begin{array}{l}\text { Forward: 5'-GTGCTGAAGGACACACACTAAAGAAGA-3' } \\
\text { Reverse: 5'-TTGCCATCCTTCTCAAAGTTGTAGG-3' }\end{array}$ & 605 & 59 \\
\hline MMP-9 & $\begin{array}{l}\text { Forward: 5'-CACTGTCCACCCCTCAGAGC-3' } \\
\text { Reverse: 5'-GCCACTTGTCGGCGATAAGG-3' }\end{array}$ & 263 & 59 \\
\hline
\end{tabular}

Table 2. Experimental group and dose design

\begin{tabular}{ccccc}
\hline \hline No. & Group & Treatment & UV irradiation & Mice (n) \\
\hline 1 & NC (Normal control) & d.w & - & 7 \\
2 & UC (UV control) & d.w & + & 7 \\
3 & PC (Positive control), retinol & $0.01 \%$ & + & 7 \\
4 & FL (Fraction I Low) & $1 \mathrm{mg} / \mathrm{mL}$ & + & 7 \\
5 & FH (Fraction I High) & $10 \mathrm{mg} / \mathrm{mL}$ & + & 7 \\
\hline
\end{tabular}


1 hairless mice were fed a standard diet (solid feed 5L79, Orient. Co. LTD, Korea) and water ad libitum, and allowed to acclimate for at least $1 \mathrm{wk}$ before the start of the experiments. These animals were $7 \mathrm{wk}$ old at the start of the experiment. These 7-wk-old mice were randomized into five groups (Table 2) with 7 mice in each group and treated on the dorsal surface with vehicle, retinoic acid $0.01 \%$ and $1 \%, 10 \%$ solutions of Fraction I $(>10 \mathrm{kDa})$. All samples were dissolved in polyethylene glycol: Ethol: DW (5:3:2). (- : not UV irradiation)

\section{UV-B irradiation}

The source of UV-B irradiation was a Philips TL60W/ 12 RS lamp (spectrum between 270 and $400 \mathrm{~nm}$ ). The mice were irradiated three times a week for $5 \mathrm{wk}$. The lamp was mounted $30 \mathrm{~cm}$ above the table where the mice were placed. The intensity of irradiation was $30 \mathrm{~mJ} / \mathrm{cm}^{2}$ (first week), $60 \mathrm{~mJ} / \mathrm{cm}^{2}$ (second week), $90 \mathrm{~mJ} / \mathrm{cm}^{2}$ (third week), $120 \mathrm{~mJ} / \mathrm{cm}^{2}$ (fourth and fifth weeks). For the precise amount of UV rays used in the study, we measured the amount of light using a UV instrument (ST510 series, Sentry, Taiwan). Starting $3 \mathrm{~d}$ before skin sampling, UV radiation was not performed, so that results would not be affected by the immediate UV skin damage (Cho, 2007; Kim, 2009).

\section{Evaluation of skin thickness}

Mice dorsal skin fold thickness was measured using a caliper (Absolute, Japan). Skin was manually pinched upward at the neck and skin fold thickness was then mea- sured mid-way between the neck and hips (Lee, 2010; Shin, 2012).

Measurement of TEWL, moisture content, skin erythema and melanin deposition

Transepidermal water loss (TEWL) and moisture content of the skin was measured from the back of hairless mice with a Tewameter (MPA5-CK, Courage+Khazaka, Germany) along with moisture content (Corneometer CM 825). Skin erythema and melanin deposition in the stratum corneum were measured with a Mexameter MX18 as and provided a melanin/erythema index. The stratum corneum and the average of three measurements within the same area are shown (Chisato et al., 2013).

\section{Real-time RT-PCR analysis from skin lesion}

To confirm the mRNA expression level from skin lesions, $1 \mathrm{~mL}$ of TRIzol reagent (Invitrogen Co., CAT. 15596026) was added to skin lesions and this was homogenized with a pestle. After homogenization, $200 \mu \mathrm{L}$ of chloroform was added and stirred for $15 \mathrm{sec}$. Centrifugation was performed for supernatant isolation at $4^{\circ} \mathrm{C}, 13,000 \mathrm{~g}$, for $15 \mathrm{~min}$ and the supernatant was transferred to a new etube. Isopropyl alcohol $500 \mu \mathrm{L}$ was added to a new e-tube and fixed for $10 \mathrm{~min}$. To eliminate the solvent, $1 \mathrm{~mL}$ of $75 \%$ ethanol was added and centrifuged at $4^{\circ} \mathrm{C}, 7500 \mathrm{~g}$, for $5 \mathrm{~min}$; this process was done twice. After ethanol elimination, ultrapure water (Invitrogen, USA) was added for the RNA template. To solubilize the RNA template completely, it was warmed at $55^{\circ} \mathrm{C}$ for $10 \mathrm{~min}$. To mea-

Table 3. Primer sequences used in this study

\begin{tabular}{|c|c|c|c|}
\hline Primer & Sequence & Size (bp) & $\overline{\mathrm{Tm}\left({ }^{\circ} \mathrm{C}\right)}$ \\
\hline GAPDH & $\begin{array}{l}\text { Forward: 5'-GAAGGTGAAGGTCGGAGTCAACG-3' } \\
\text { Reverse: 5'-AGTCCTTCCACGATAACCAAAGTTG-3' }\end{array}$ & 384 & 58 \\
\hline IL-1â & $\begin{array}{l}\text { Forward: 5'- ATGGCAACTGTTCCTGAACTCAACT-3' } \\
\text { Reverse: 5'- CAGGACAGGTATAGATTCTTTCCTTT-3' }\end{array}$ & 563 & 58 \\
\hline IL-6 & $\begin{array}{l}\text { Forward: 5'-CCACTTCACAAGTCGGAGGCTTA-3' } \\
\text { Reverse: 5'-AATTTCCTGATTATATCCAGTTTGG-3' }\end{array}$ & 185 & 58 \\
\hline VEGF & $\begin{array}{l}\text { Forward: 5'-CTGGATATGTTTGACTGCTGTGGA-3' } \\
\text { Reverse: 5'-GTTTCTGGAAGTGAGCCAATGTG-3' }\end{array}$ & 180 & 58 \\
\hline $\mathrm{COX}-2$ & $\begin{array}{l}\text { Forward: 5'- CCAGATGCTATCTTTGGGGAGAC-3' } \\
\text { Reverse: 5'- GCTTGCATTGATGGTGGCTG-3' }\end{array}$ & 249 & 58 \\
\hline EGF & $\begin{array}{l}\text { Forward: 5'-CATCATGGTGGTGGCTGTCTG-3' } \\
\text { Reverse: 5'-CACTTCCGCTTGGCTCATCA-3' }\end{array}$ & 137 & 58 \\
\hline COL1A1 & $\begin{array}{l}\text { Forward: 5'-CTCCGGCTCCTGCTCCTCTTA-3' } \\
\text { Reverse: 5'-GCACAGCACTCGCCCTCCC-3' }\end{array}$ & 233 & 58 \\
\hline MMP-1 & $\begin{array}{l}\text { Forward: 5'-CAAGGACCCAGGAGCCCTGAT-3' } \\
\text { Reverse: 5'-CCCAGGTCAGATATTTTTCTGGG-3' }\end{array}$ & 423 & 58 \\
\hline MMP-2 & $\begin{array}{l}\text { Forward: 5'-CACCTACACCAAGAACTTCC-3' } \\
\text { Reverse: 5'-AACACAGCCTTCTCCTCCTG-3' }\end{array}$ & 333 & 58 \\
\hline MMP-9 & $\begin{array}{l}\text { Forward: 5'- TAGTGAGAGACTCTACACAG-3' } \\
\text { Reverse: 5'- CCACTTCTTGTCAGTGTCGA-3' }\end{array}$ & 340 & 58 \\
\hline
\end{tabular}


sure the RNA template concentration, a spectrophotometer was used. A 10- $\mu \mathrm{L}$ mixture comprised of $1 \mu \mathrm{g}$ of total RNA template mixed with 300 pmol random primer and ultrapure water (Invitrogen, USA) was heated at $65^{\circ} \mathrm{C}$ for 5 min. To synthesis cDNA, $4 \mu \mathrm{L}$ of $5 \mathrm{X}$ RTase M-MLV buffer, $10 \mathrm{mM}$ dNTP mixture, RTase M-MLV (Takara, 2640A, Japan) and ultrapure water were added to make a total volume of $20 \mu \mathrm{L}$, which was incubated at $37^{\circ} \mathrm{C}$ for $50 \mathrm{~min}$ and heated at $70^{\circ} \mathrm{C}$ for $10 \mathrm{~min}$. The cDNA was analyzed by Thermal Cycler Dice (Takara, TP800, Japan) using the power SYBR premix Ex Taq (Takara, RP041A, Japan) and specific oligonucleotide primers as follows (Table 3).

\section{Histopathology}

Dorsal skins $(1 \mathrm{~cm} \times 1 \mathrm{~cm})$ were fixed with a $10 \%$ formalin neutral buffered solution, embedded in polyester wax and sectioned at $6 \mathrm{~mm}$. The sections were subjected to hematoxylin and eosin (H\&E) and Masson's trichrome staining (Lee, 2010).

\section{Skin replica and image analysis}

After sacrifice, negative replicas of the dorsal skin surface were taken using a silicon-based impression material. Replicas of mouse dorsal skin were prepared using SILFLO resin (SILPRO, Silflo Primer, USA) and analyzed by an imaging camera (USB digital microscope, China).

\section{Statistical analysis}

All of the data were treated for significance using oneway analysis of variance (ANOVA) at $p<0.05$ with IBM SPSS Statistics 19.0 (IBM Corporation, Somers, USA). Data were analyzed using ANOVA followed by Tukey's and Duncan's tests. Results were considered significant when $p<0.05$, unless otherwise stated.

\section{Results}

\section{Effects of collagen synthesis of ESMH in CCD-} 986Sk cells (human dermal fibroblast)

Measurements confirming ESMH effects on procollagen synthesis in vitro showed a dependent increase of expression of procollagen (Fig. 1). TGF- $\beta(10 \mathrm{ng} / \mathrm{mL})$ as a positive control showed $8 \mathrm{ng} / \mathrm{ml}$ procollagen expression level and ESMH showed a similar expression level at $0.01 \mathrm{mg} / \mathrm{mL}$. Fraction I (>10 kDa) expressed $12.6 \mathrm{ng} / \mathrm{mL}$ and $17.2 \mathrm{ng} / \mathrm{mL}$ at $0.1 \mathrm{mg} / \mathrm{mL}$ and $1 \mathrm{mg} / \mathrm{mL}$ respectively, which showed more than two times expression of the positive control. Whole ESMH and Fraction III $(<3 \mathrm{kDa})$

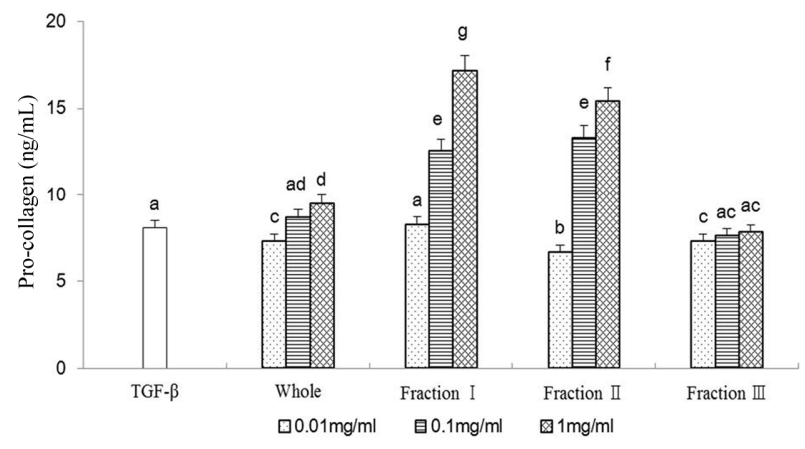

Fig. 1. Collagen synthesis of ESMH in CCD-986Sk cells (human dermal fibroblast). The amount of both Collagen synthesis from supernatant of CCD-986Sk cells was measured using an pro-collagen kit. CCD-986Sk cells were treated with $0.01,0.1$, and $1 \mathrm{mg} / \mathrm{mL}$ of the fractional extracts. Whole indicates ESMH before fractionation (lane Whole). TGF- $\beta(10 \mathrm{ng} / \mathrm{mL})$ was used as a control (lane TGF- $\beta$ ). The pro-collagen synthesis was significantly increased in the Fraction I $(>10 \mathrm{kDa})$ cells compared with the TGF- $\beta$ treated cells. Values are presented as mean $\pm \mathrm{SD}(\mathrm{n}=3)$. Data are statistically different $(p<0.05)$ among those columns with different symbols. The order of value is termed as order of alphabet.

expressed procollagen, but an increase depending on concentration of hydrolysates was not shown. Fractions of ESMH other than, Fraction III $(<3 \mathrm{kDa})$, increased procollagen synthesis more effectively in the fibroblast of the inner skin.

Effects of ESMH on the amount of MMP-1 released by CCD-986Sk cells (human dermal fibroblast)

Effects of ESMH on biosynthesis of MMP-1 were measured (Fig. 2). Expression of MMP-1 of control by UV irradiation was $18.9 \mathrm{ng} / \mathrm{mL}$, which showed that treatment of Fraction I decreased inversely. In particular, biosynthesis levels of MMP-1 produced by UV irradiation were 13 $\mathrm{ng} / \mathrm{mL}$ at $1 \mathrm{mg} / \mathrm{mL}$ and decreased by $28 \%$. Inhibition effects of MMP-1 biosynthesis compared to the positive control were somewhat low, but ESMH inhibited expression of MMP-1, which showed the potential for the use of EMSH as a functional cosmetic material to reduce wrinkles by inhibition of collagen degradation in skin.

\section{Effects of ESMH on the amount of HA released by HaCaT cells (human keratinocyte)}

The amount of HA which is a hydrophilic substrate with a moisture function was measured by treating ESMH in $\mathrm{HaCaT}$ cells (Fig. 3). All fractions of hydrolysates except for Fraction III with low molecular weight expressed high HA. Even though the amount of HA release was similar 


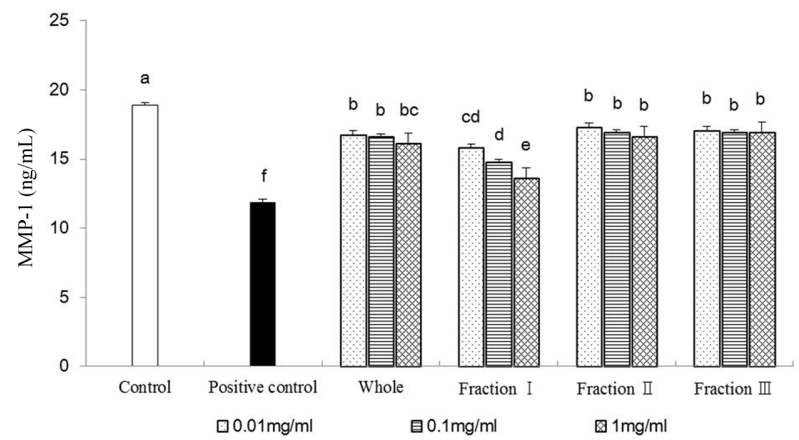

Fig. 2. Effect of the ESMH fractionated by molecular weight on MMP-1. MMP-1 levels were measured in the CCD986Sk cells culture media by ELISA. CCD-986Sk cells were treated with $0.01,0.1$, and $1 \mathrm{mg} / \mathrm{mL}$ of the fractional extracts. Ascorbic acid was used as a positive control $(0.2 \mathrm{mM})$. Whole indicates ESMH before fractionation (lane Whole). TNF- $\alpha$ was added at a concentration of 10 $\mathrm{ng} / \mathrm{mL}$ in order to enhance the activity of MMP-1 (all lanes). Values are presented as mean $\pm \mathrm{SD}(\mathrm{n}=3)$. Data are statistically different $(p<0.05)$ among those columns with different symbols. The order of value is termed as order of alphabet.

to the control at $0.01 \mathrm{mg} / \mathrm{mL}$, it steadily increased depending on the concentration of treatment. The amount of HA released was $1,099 \mathrm{ng} / \mathrm{ml}, 1,562 \mathrm{ng} / \mathrm{ml}$ and $1,525 \mathrm{ng} / \mathrm{ml}$, respectively, in whole hydrolysates, Fraction I, and Fraction II. The treatment of TGF- $\beta(10 \mathrm{ng} / \mathrm{mL})$ known to prompt HA synthesis released $290 \mathrm{ng} / \mathrm{ml} \mathrm{HA}$, but fractions of hydrolysates showed an increase of more than 5 times. A comparison of the amount of HA released by treatment of TGF- $\beta$ and fraction of hydrolysates at several concentrations indicates the possibility that ESMH could be used as a cosmetic material for increasing skin moisture content.

\section{Levels of COX-2, MMP-2, 9 and COLIA1 mRNA} determined by real-time RT-PCR analysis by CCD986Sk cells (human dermal fibroblast)

The mRNA expression level in CCD-986Sk cells irradiated with UV was measured. The mRNA level of COL $1 \mathrm{~A} 1$, which is a factor related to production of collagen, the mRNA level of COX-2 which is a factor related to production of pro-inflammatory cytokine, and the mRNA level of MMP-2, 9 which is a factor related to dissolution of collagen were measured (Fig. 4). In the UC group, the pro-inflammatory, mRNA expression levels, an indicator of collagen degradation, increased. These mRNA expression levels decreased in Fraction I; this was measured by the positive control group which processes TGF-(10 ng/

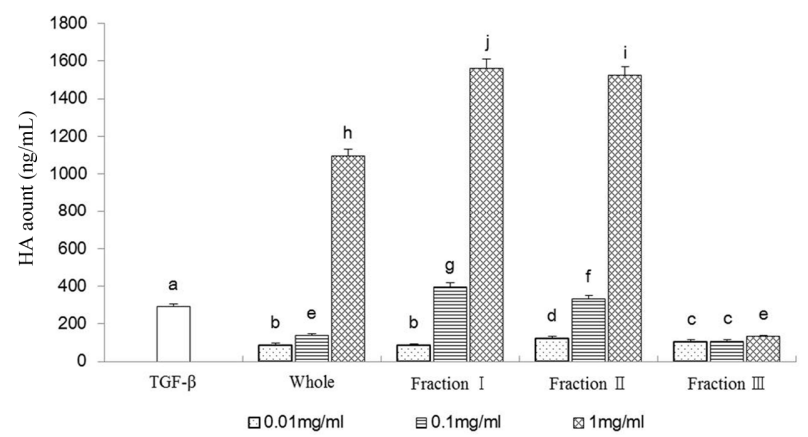

Fig. 3. Effects of ESMH on the amount of HA released by HaCaT cells. HA levels were measured in the $\mathrm{HaCaT}$ cells culture media by ELISA. HaCaT cells were treated with $0.01,0.1$, and $1 \mathrm{mg} / \mathrm{mL}$ of the fractional extracts. TGF- $\beta(10 \mathrm{ng} / \mathrm{mL})$ was used as a control (lane TGF- $\beta$ ). The HA levels was significantly increased in the Fraction I $(1 \mathrm{mg} / \mathrm{mL})$ cells compared with the TGF- $\beta$ treated cells. Values are presented as mean $\pm \mathrm{SD}(\mathrm{n}=3)$. Data are statistically different $(p<0.05)$ among those columns with different symbols. The order of value is termed as order of alphabet.

$\mathrm{mL}$ ) PC and the level which is similar to the expression ratio. The mRNA expression ratio of these generation of collagen indexes confirmed in the UV military by the UV irradiation to be reduced. The level of expression profile was shown and it is similar to the positive control group (PC) military processing this TGF $-\mu(10 \mathrm{ng} / \mathrm{mL})$ it could confirm that collagen formation ability of the cell is increased. In the extrinsic aging process of physiological aging and UV rays, it could be confirmed at the gene level that ESMH induces the production of collagen by UV irradiation and lysis inhibition and inflammation control through the index factors commonly observed in the material.

\section{Skin thickness of hairless mouse supplemented with Fraction I (> 10 kDa)}

The neck site tissue of the hairless mice control group (receiving UV radiation) was $570 \mu \mathrm{m}$ thick, thicker than the normal control group $(450 \mu \mathrm{m})$. PC, FL and FH groups (receiving UV radiation) had skin thicknesses of $525 \mu \mathrm{m}$, $480 \mu \mathrm{m}$, and $470 \mu \mathrm{m}$ respectively. ESMH as retinol and UV irradiation of the skin was measured to determine the effects (Fig. 5(A)). It was found that ESMH treatment suppressed increases in skinfold thickness due to the UV irradiation. The thickness of the tissue increased in response to irradiation with UV; it changed from $600 \mu \mathrm{m}$ (NC) to $1,030 \mu \mathrm{m}$ (UC). Skin thickness in the PC (retinol $0.01 \%$ ) group was $780 \mu \mathrm{m}$, FL was $670 \mu \mathrm{m}$, and FH was 
$\operatorname{cox} 2$
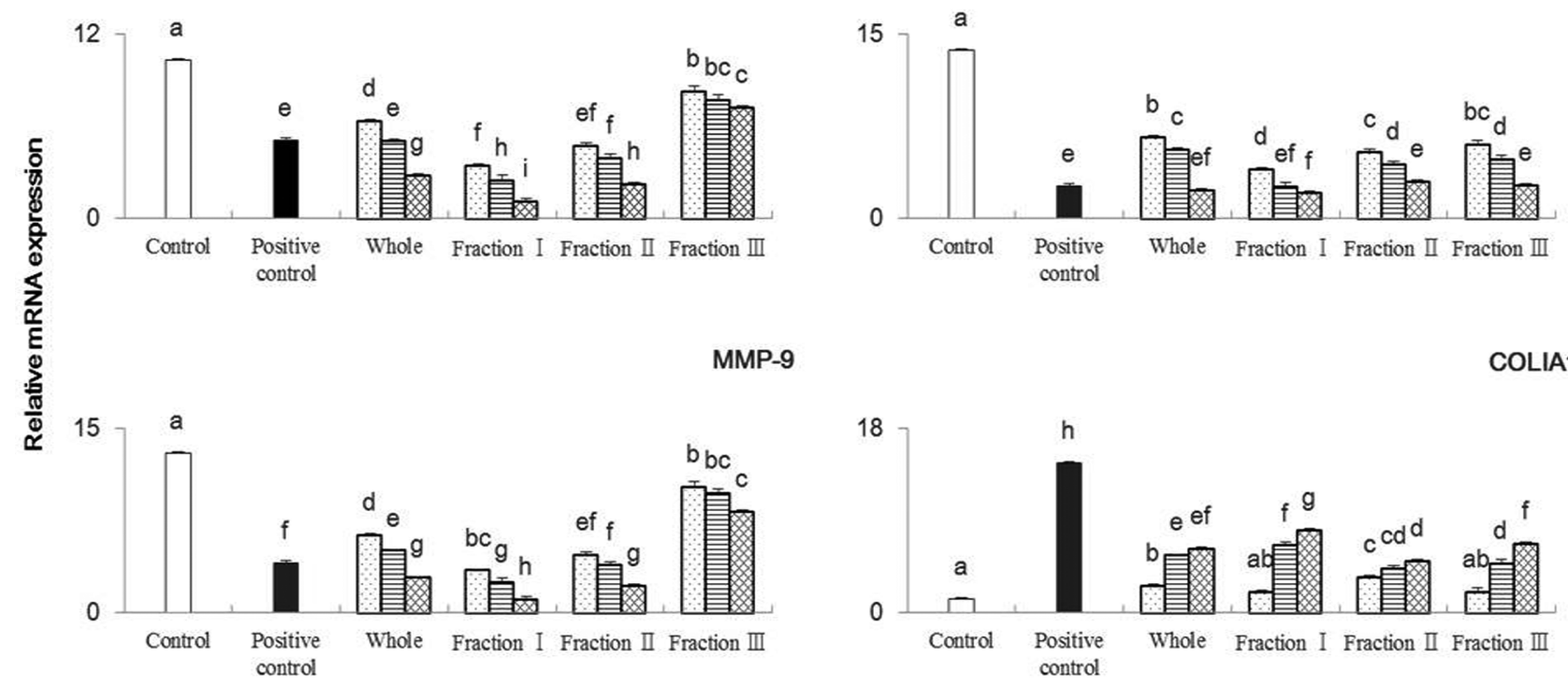

MMP-9

COLIA1

$\square 0.01 \mathrm{mg} / \mathrm{ml}$ 目 $0.1 \mathrm{mg} / \mathrm{ml} \quad 01 \mathrm{mg} / \mathrm{ml}$

Fig. 4. Effect of ESMH on the cytokine mRNA expression in human skin markers. CCD-986Sk cells were treated with $0.01,0.1$, and $1 \mathrm{mg} / \mathrm{mL}$ of the fractional extracts and mRNA expressions of aging genes encoding COLIA1, MMP 2, 9 and COX2 were measured by real-time PCR. Increased levels of MMP 2, 9 and COX2 in the control cells were significantly suppressed in the Fraction I cells. Values are presented as mean \pm SD $(n=3)$. Data were analyzed using ANOVA followed by Tukey's and Duncan's test. Data are statistically different $(p<0.05)$ among those columns with different symbols. The order of value is termed as order of alphabet.
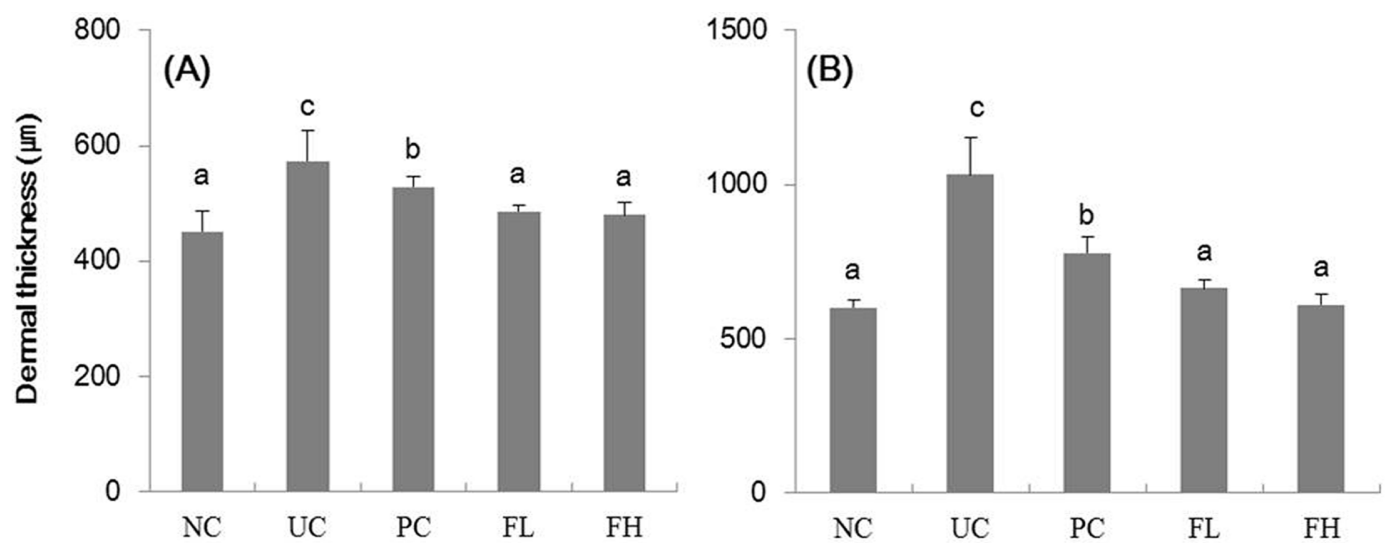

Fig. 5. Skin thickness of hairless mouse treat supplemented with Fraction I. Dorsal skin-fold thickness was measured using a caliper (A) Neck, (B) Hip. Values represent the mean SD ( $\mathrm{n}=7)$. Data were analyzed using ANOVA followed by Tukey's and Duncan's test. Data are statistically different $(p<0.05)$ among those columns with different symbols. The order of value is termed as order of alphabet. NC, Normal control; UC, UV control; PC, Positive control of retinoic acid 0.01\%; FL, UV + Sample of 1 $\mathrm{mg} / \mathrm{d} ; \mathrm{FH}, \mathrm{UV}+$ Sample of $10 \mathrm{mg} / \mathrm{d}$; Fraction I, above $10 \mathrm{kDa}$.

$605 \mu \mathrm{m}$ (Fig. 5(B)). This result is due to the UV irradiation due to damaged skin barrier ESMH thickened skin treatment through inhibition of the hydrolysate was found to be capable of. Retinol skin treatment through the thick- ness of the positive control group than in a superior protective effect against UV rays can be measured with a new UV-blocking cosmetic materials were able to confirm the possibility. 

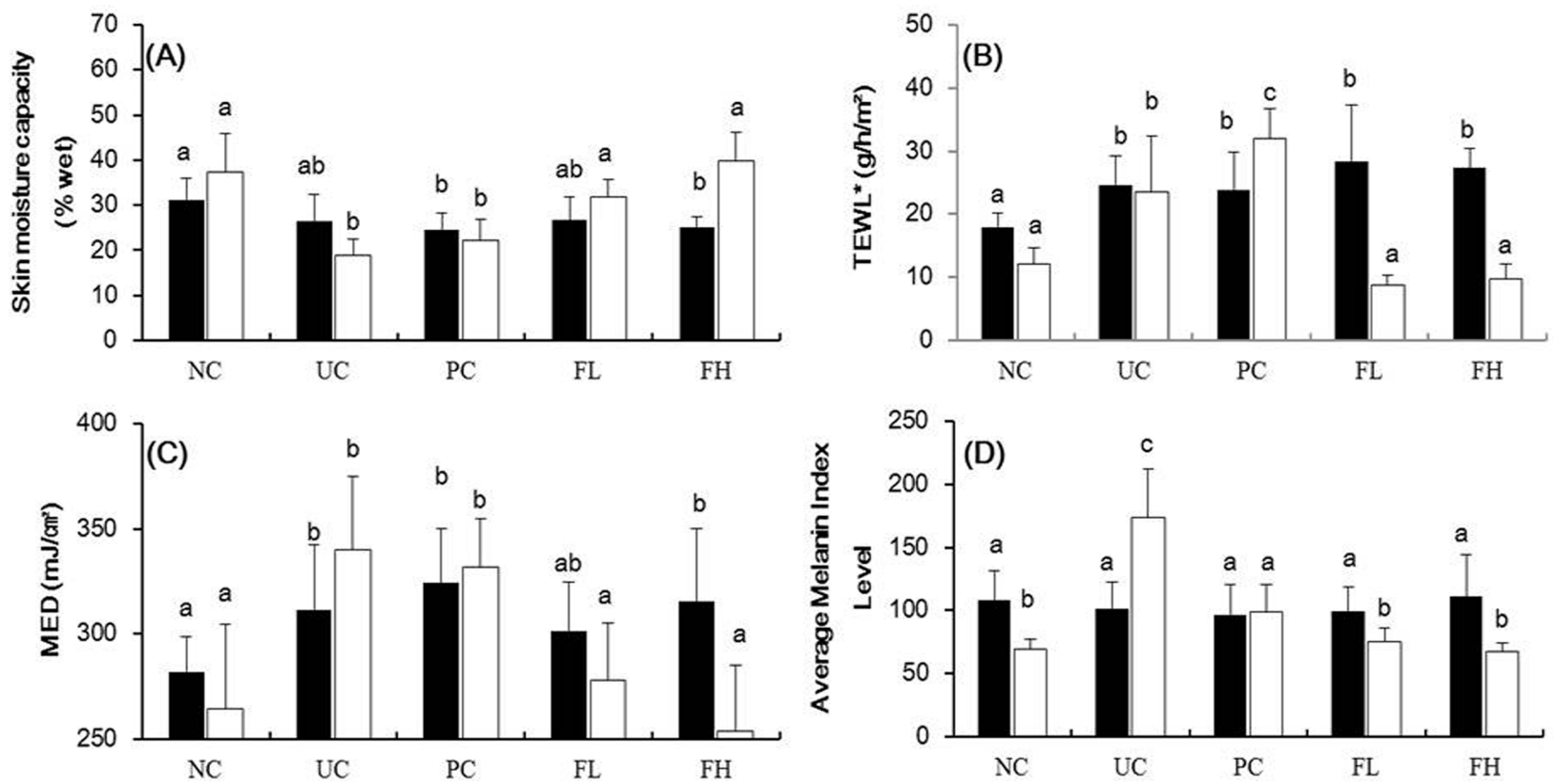

Fig. 6. Effects of the ESMH fractionated by Fraction I. (A) skin moisture, (B) TEWL, (C) Erythema, (D) Mexameter on UV-B irradiated hairless mouse skin. The interpretation of the corneometer results: Normal room condition $\left(20-25^{\circ} \mathrm{C}\right.$ and $40-60 \%$ air humidity). Values represent the mean SD ( $\mathrm{n}=7)$. Data were analyzed using ANOVA followed by Tukey's and Duncan's test. Data are statistically different $(p<0.05)$ among those columns with different symbols. The order of value is termed as order of alphabet. NC, Normal control; UC, UV control; PC, Positive control of retinoic acid 0.01\%; FL, UV + Sample of $1 \mathrm{mg} / \mathrm{d}$; FH, UV + Sample of $10 \mathrm{mg} / \mathrm{d}$. $\square$ : $0 \mathrm{wk}, \square: 5 \mathrm{wk}$.

\section{Anti-wrinkle effect of Fraction I determined by arithmetic average}

Changes in the skin moisture content of mice receiving UV irradiation were measured (Fig. 6(A)). The skin moisture content of the normal control group (NC) was high in comparison with other test groups receiving UV irradiation for the experimental period. After being sampled at $5 \mathrm{wk}$, the moisture content was reduced in the UC group, while the PC group did not show a significant difference. In FL and FH groups, the increase in the moisture content was measured. The $\mathrm{FH}$ group showed an increase in moisture content from $25 \%$ to $40 \%$ and show the NC group and equivalent moisture content. The amount of moisture loss of the skin was measured through the measurement of the transepidermal water loss of mice, and showed a tendency similar to the results of moisture content. In the early stage of the experiment with UV irradiation, moisture loss degrees were high, but the loss degrees reduced after $5 \mathrm{wk}$ when the sample was processed. The moisture loss degrees of the PC group indicated a return value in which the moisture amount of loss was not regained by the processing of retinol and the amount of moisture loss reduction; FL and FH groups had lower moisture loss than in the NC group (Fig. 6(B)). This re- sult confirmed that ESMH could increase moisture content and counter the loss generated by the breakdown of the skin barrier due to UV rays. In addition, it is considered that application as the functionality cosmetic material for the moisture maintenance of the skin is possible, confirming the experimental result of the moisturizing relation in vitro of the ESMH performed previously. The results of measuring the erythema index and growth amount of the melanotic pigment as shown in Figs. 6(C) and (D) were the same. The result of measuring the change of erythema after $5 \mathrm{wk}$ of experiment and UC indicated the difference in which erythema could be observed by the UV irradiation and to increase which PC is particular in spite of the processing of retinol in the erythema index. However, in the process group of the ESMH, it was measured and that erythema reduced by the sample application the reduction of rapid erythema was confirmed in particularly, FH. Similarly, the melanin pigmentation index number was increased by about 175 in the measurement of the growth of melanotic pigment in the case of $\mathrm{UC}$ by the UV irradiation in 100. For UC, the positive control group melanin pigmentation index was increased to $100-$ 175 by the UV irradiation was not observed before and after difference retinol similarly processed result of mea- 
suring the deposition of melanin. The process of the ESMH, the degree of pigmentation at the level similar to $\mathrm{NC}$ is slightly decreased was observed. Consequently, the reduction of the ESMH is increased by UV irradiation pigmentation and the erythema index was confirmed. And there are estimated to be the effect on the skin erythema and impediment of the melanin pigmentation. Thus, in vivo results of whitening related skin confirmed those of in vitro; ESMH blocked both UV-B involved in erythema and UV-A involved in pigmentation Fraction I is considered to have potential as a UV blocking functional cosmetics material.

\section{Real-time RT-PCR analysis from skin lesion}

The mRNA expression level in hairless mice irradiated with UV light was measured. Fig. 7(A) shows the results
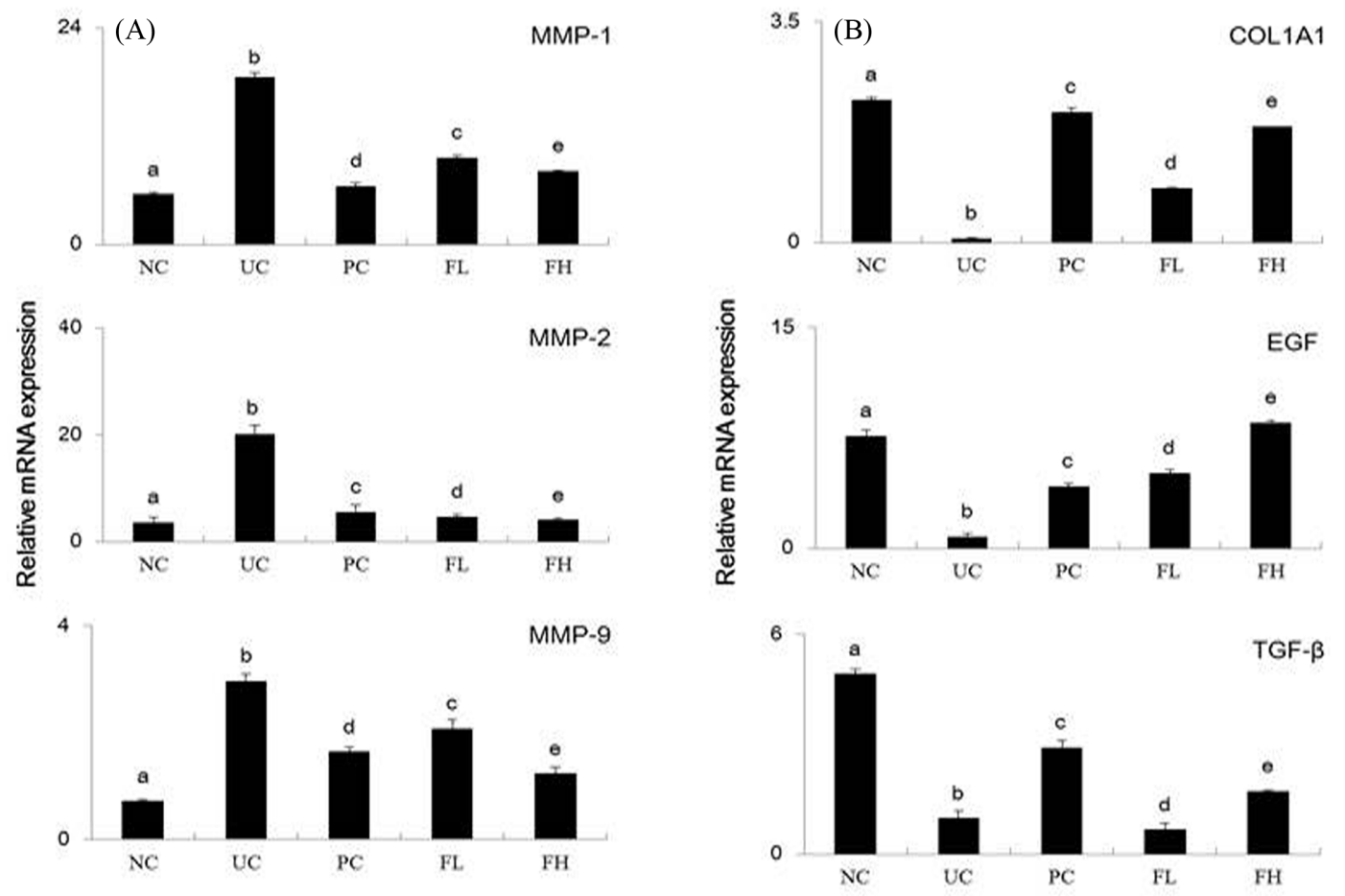

(C)
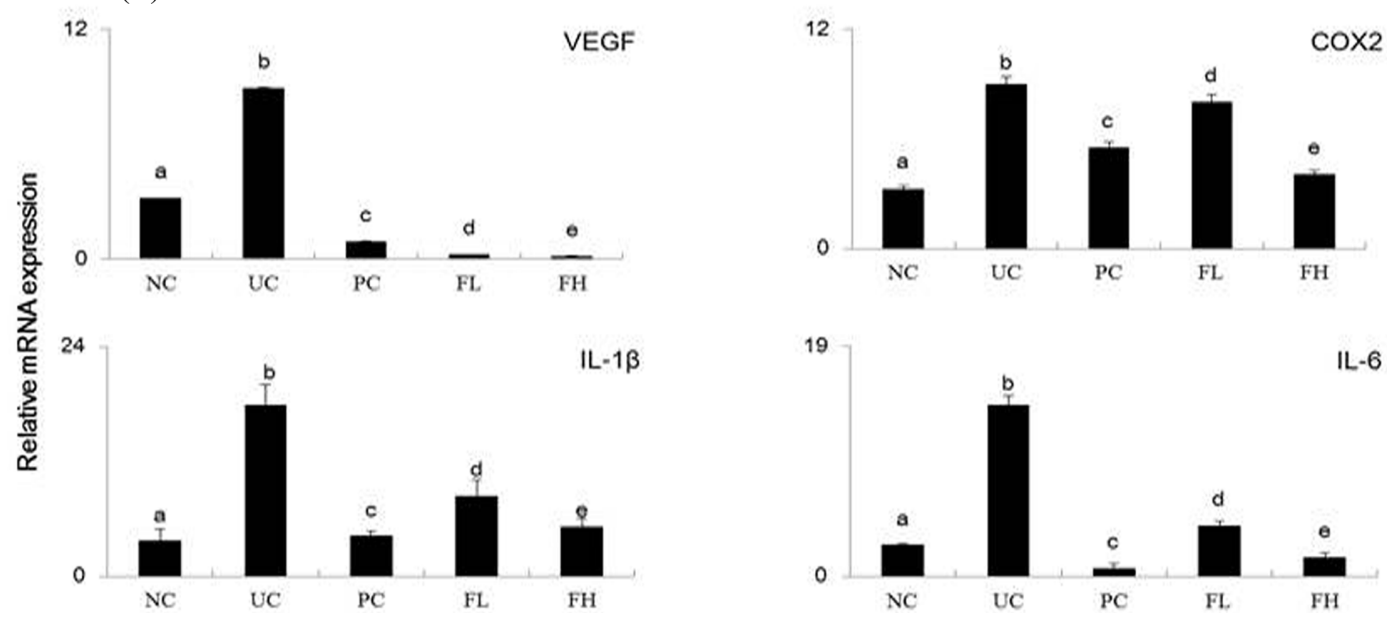

Fig. 7. Effect of ESMH on the cytokine mRNA expression in mouse skin tissue. The relative level of expression of MMP-1, 2, 9 (A), COL1A1, EGF, TGF- $\beta$ (B) and COX2, VEGF, IL-1 $\beta$, IL-6 (C) in the mouse skin, normalized to GAPDH, was determined by Real-time PCR. Data are presented as the mean $\pm \mathrm{SD}(\mathrm{n}=7)$. Data were analyzed using ANOVA followed by Tukey's and Duncan's test. Data are statistically different $(p<0.05)$ among those columns with different symbols. The order of value is termed as order of alphabet. NC, Normal control; UC, UV control; PC, Positive control of retinoic acid 0.01\%; FL, UV + Sample of $1 \mathrm{mg} / \mathrm{d}$; FH, UV + Sample of $10 \mathrm{mg} / \mathrm{d}$. 
of measuring the mRNA expression amount of MMP-1, 2 and 9 that degrade the collagen index. It was determined that for the UC group, mRNA expression level as an indicator of collagen degradation is increased by UV irradiation. Furthermore, it was confirmed that the expression level of mRNA of these indicators is reduced in $\mathrm{FH}$, which measured at levels similar to PC expression levels. Fig. 7(B) shows the results of measuring the mRNA expression level of COL1A1, EGF, and TGF- $\beta$ is an index involved in the production of collagen. The mRNA expression ratio of the generation of collagen confirmed in UC by the UV irradiation to be reduced. The level of expression profile was shown and it is similar to $\mathrm{NC}$ in which FH doesn't irradiate the UV rays in the result of measuring the mRNA expressed grade of the COL1A1 and EGF it could confirm that collagen formation ability of the cell is increased. The mRNA level of COX2, VEGF, IL-1 $\beta$ and IL-6, which is a factor related to pro- duction of pro-inflammatory cytokine Fig. 7(C). The thing in which the mRNA expression ratio of the induction of inflammation index is increased by the UV irradiation in UC was measured. The reduction which is remarkable in comparison with UC irradiating the mRNA case UV rays of FH was shown and it was revealed as the level which is similar to NC. It confirmed that there was inflammation generated due to the UV irradiation effect and it suppressed the extracellular matrix protein disintegration. In addition, in VEGF, it was lower than in NC and the ESMH treatment was equal in not only FH, but also FL. As a result, in the extrinsic aging process due to physiological aging and UV rays, it was confirmed at the gene level that ESMH induces an increase in collagen by UV irradiation and lysis inhibition and inflammation control through the index factors commonly observed in the material. Furthermore, not only the FH process ESMH was lower than NC, VEGF showed similar results even FL.

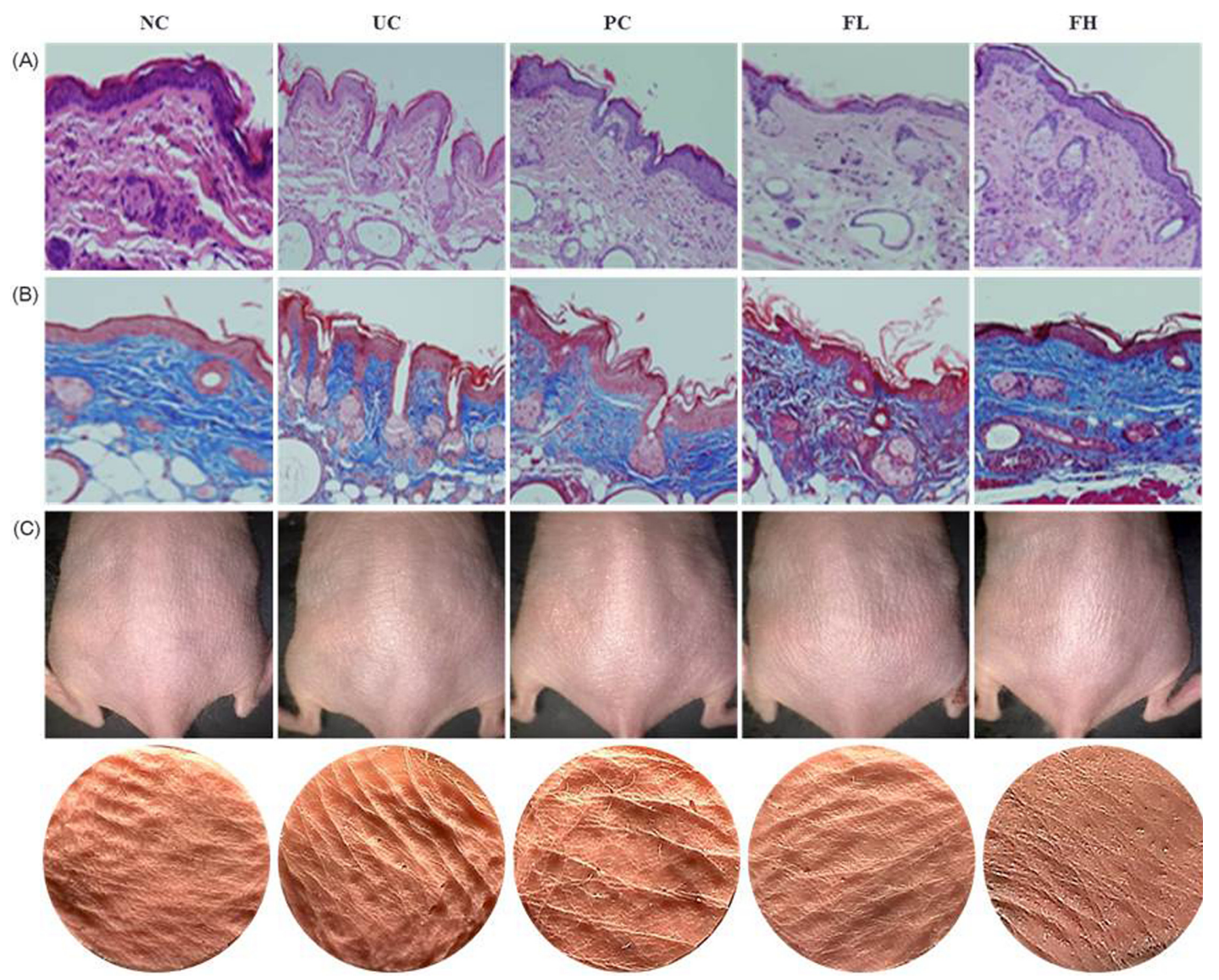

Fig. 8. Histological observation on SKH-1 hairless mouse skin after 5-week application of test compounds. (A) H\&E, (B) Masson's trichrome stain, and (C) Photographs of skin surface (top panel) and its skin replicas (bottom panel) the hairless mice. Collagen fibers were stained blue, and collagen contents were significantly increased in the middle and high doses of FH (B). The FL, FH treated group appeared to have fewer wrinkles than the UV control group (C). NC, Normal control; UC, UV control; PC, Positive control of retinoic acid 0.01\%; FL, UV + Sample of $1 \mathrm{mg} / \mathrm{d}$; FH, UV + Sample of $10 \mathrm{mg} / \mathrm{d}$; Fraction I, above $10 \mathrm{kDa}$. 


\section{Histopathological findings, skin replica and image analysis}

In the results of tissue stained by hematoxylin and eosin, the skin surface was increased 2 to 3 times more in thickness in the UC case than the NC case. It also had an influence on the formation of thick and deep wrinkles, and there was a noticeable increase in hair follicle size. There was a great degree of polymorphism on the corneous cell, even in the outer layer. By comparison, FL and $\mathrm{FH}$ of hydrolysate fraction of ESM was appeared to aspect of decreasing thickness of skin surface and so was in NC case (Fig. 8(A)).

In the results of the observation of the density of the inner corium after the Masson's trichrome staining, the UC treatment of the hydrolysate fraction of ESM showed signs of regular arrangement and increased amount of collagen fiber density, and this result was found in the NC case as well. FH of Fraction I had a better effect than FL of Fraction I on the improvement of collagen fibers (Fig. 8(B)). The effects of treatment with ESMH on the skin wrinkles of hairless mice irradiated by UV rays were examined. After the experiment, the degree of wrinkle formation visible in close-up of the naked eye one the mouse's skin was scanned by silicon rubber which is a function of its replica for detail observation. After the UV irradiation period, through visual observation it was confirmed that the increase of skin wrinkles in the UV group (UV control group) was pronounced compared to the NC group (normal control group). In addition, a higher concentration of ESMH significantly increased the suppression of wrinkles, NC group of similar degree showed good skin condition. (Fig. 8(C)).

\section{Discussion}

Skin is a part of the human body that is exposed to UV rays and this leads to wrinkles, loss of elasticity, freckles, and the loss of its power to repair damage. Photoaging is the most common form general of skin damage due to repetitive UV exposure over a long period of time. This also causes extracellular matrix (ECM) damage (Chung, 2003; Jenkins, 2002; Rittie and Fisher, 2002). UV-B irradiation induces aging and it suppresses the function of tissue immunity and can lead to the outbreak of skin cancer. It also leads to early aging. Wrinkle formation is a typical symptom of aging skin. Chronic exposure to UV rays makes MMPs increase and this leads to the breakdown of collagen fibers. As a result, this causes a deficit of collagen fibers and leads to wrinkle formation (Gloster and
Neal, 2006; Green, 1991). The lack of collagen fibers weakens the cells of the corium, delays the treatment function, reduces angiogenesis, and leads to thin skin. There are plentiful collagen fibers in the newly formed corium, while there are poor ones in the old corium due to segmentation of collagen fibers (Bae et al., 2009; Fisher et al., 1997). A deficiency of collagen fibers in the dermis weakens the function of cells, causes a delay in wound healing, angiogenesis, and results in thin skin. New, undamaged collagen fibers in the dermis are rich, and old collagen fibers in the dermis have a sloppy form (Vayalil et al., 2004). In addition, retinoic acid, which can be used as a wrinkle remedy, improves wrinkles and skin elasticity with application of for several months to a year or more. Retinol is a type of vitamin A and has an effect on skin photoaging and wrinkle improvement (Saurat and Sorg, 1999).

However, overuse of retinoic acid has negative side effects such as dermatitis. Therefore, studies are actively underway on natural substances that have safe antioxidant effects on the human body. Because there are no side effects on the human body, safe natural substances are have created a lot of interest in the field in recent years, and these studies are being actively performed (Cong et al., 2008; Fisher et al., 1996). ESM is an organic substance that has been shown to increase cellular activity and collagen production. Furthermore, ESM prevents skin aging and reduces damage caused by UV-light and infla- mmation (Candilish and Scougall, 1969). It is proposed that ESM which are currently disposed as waste could be used in the production of functional cosmetics.

In this study, ESMH was investigated using CCD986Sk (human fibroblast cells) and Fraction I was highest in collagen synthesis, greater than TGF- $\beta$ in elasticity and wrinkle improvement of skin. When TNF- $\alpha$ caused activity of MMP-1 in CCD-986Sk cells, the whole and Fraction I proved to be effective in hindering the induction of collagenase depending on the concentration, and also showed outstanding effects in suppressing skin aging. ESMH suppressed pro-collagenase enzymes (MMPs such as MMP-2, 9) and it also enhanced COLI1A1. With in vivo testing, we investigated the effects of UV exposure on skin aging, particularly on the development of skin wrinkles, in a hairless mouse model. Increases in connective tissues may increase epidermal, keratin and skin fold thickness and lead to the formation of skin wrinkles by UV irradiation in hairless mice. Skinfold may become thin due to natural aging, or the formation of the keratin layer may be increased by UV rays and the skin may become 
thick (Yoshinori et al., 1995). The suppression effects of Fraction I $(>10 \mathrm{kDa})$ were measured through real time RT-PCR and histopathology. Collagen mRNA levels significantly and markedly increased compared to the UC group. In MMP-1, inflammation mRNA levels were significantly reduced compared to the UC group. Skin measurements showed the moisture protection effects of skin with regard to moisture retention in mice with a relatively low loss rate in skin, which enabled us to confirm that the hydrolyzed fractions of Fraction I (FL, FH) form a superior protective layer of moisture. In addition, the reduction of rapid erythema and melanotic pigment was confirmed in the high concentration process group. Through the measurement of skin, topical Fraction I (FL) treatment in hairless mice resulted in the clear appearance of fine wrinkles, while chronic UC showed deep and irregular wrinkles without a particular orientation. Conssquently, we found that collagen and hyaluronic acid biosynthesis was increased along with the level of concentration. Moreover, we also discovered that an increased level of concentration inhibited collagenase (MMP-1) activity. Thus, we have concluded that EMSH helps to mitigate UV-B radiation-induced wrinkles and can be used for functional cosmetic materials.

\section{Acknowledgements}

We thank the SungKyun Biotech Co., LTD R\&D center, and the Functional Food Engineering Lab for the use of equipment, and we are grateful to Min-ji Kim.

\section{References}

1. Bae, J. Y., Lim, S. S., Kim, S. J., Choi, J. S., and Park, J. S. (2009) Bog blueberry anthocyanins alleviate photoaging in UV-B irradiation-induced human dermal fibroblasts. Mol. Nutr. Food Res. 53, 726-738.

2. Candilish, J. K. and Scougall, R. K. (1969) L-5-hydroxylysine as aconstituent of the shell membrane of the hen's egg. Int. J. Protein Res. 1, 299-302.

3. Chisato, O., Hiroki, O. R., Masashi, M. F., Kyoko, I., Satomi, I. K., and Keiko, K. W. (2013) Collagen hydrolysate intake improves the loss of epidermal barrier function and skin elasticity induced by UVB irradiation in hairless mice. Photodermatol. Photoimmunol. Photomed. 29, 204-211.

4. Cho, H. S. (2007) Anti-wrinkling effects of the mixture of vitamin $\mathrm{C}$, vitamin $\mathrm{E}$, pycnogenol and evening primrose oil, and molecular mechanisms on hairless mouse skin caused by chronic UV B irradiation. Photodermatol. Photoimmunol. Photomed. 23, 155-162.

5. Chung J. H. (2003) Photoaging in Asians. Photodermatol.
Photonimmunol. Photomed. 19, 109-121.

6. Cong, C. A., Wan, S. H. U., Jiang, Q. I. N., Amaral, A. L., Shan, L. U., and Gang, H. U. (2008) All-trans retinoic acid attenuates UV radiation-induced down-regulation of aquaporin-3 and water permeability in human keratinocytes. J. Cellular Physiol. 215, 506-516.

7. Fisher, G. J., Datta, S. C., Talwar, H. S., Wang, Z. Q., and Varani, J. (1996) Molecular basis of sun-induced premature skin ageing and retinoid antagonism. Nature 379, 335-339.

8. Fisher, G. J., Wang, Z. Q., Datta, S. C., Varani, J., Kang, S., and Voorhees, J. J. (1997) Pathophysiology of premature skin aging induced by UV light. N. Engl. J. Med. 337, 1419-1429.

9. Gloster, H. M. and Neal, K. (2006) Skin cancer in skin of color. J. American Academy of Dermatol. 55, 741-760.

10. Gonzaga, E. R. (2009) Role of UV light in photodamage, skin aging, and skin cancer: importance of photo protection. Am. J. Clin. Dermatol. 1, 19-24.

11. Green, A. C. (1991) Premature ageing of the skin in a Queensland population. Med. J. Australia 155, 473-4, 477-8

12. Haratake, A., Uchida, Y., and Schmuth, M. (1998) UVBinduced alterations in permeability barrier function: Roles for epidermal hyperproliferation and thymocyte-mediated response. J. Invest. Dermatol. 108, 769-775.

13. Held, E., Sveinsdottir, S., and Agner, T. (1999) Effect of long term use of moisturizer on skin hydration, barrier function and susceptibility to irritants. Acta. Dermatol. Veneresol. 79, 49.

14. Iwai, K., Hasegawa, T., Taguchi, Y., Morimatsu, F., Sato, K., and Nakamura, Y. (2005) Identification of food derived collagen peptides in human blood after oral ingestion of gelatin hydrolysates. J. Agr. Food Chem. 53, 6531-6536.

15. Jenkins, G. (2002) Molecular mechanisms of skin aging. Mech. Ageing Dev. 123, 801-810.

16. Jiang, S. J., Chu, A. W., Lu, Z. F., Pan, M. H., Che, D. F., and Zhou, X. J. (2007) UV B-induced alterations of the skin barrier and epidermal calcium gradient. Exp. Dermatol. 16, 985992.

17. Kang, H. H. (1997) Anti-aging in cosmetics. J. Soc. Cosmet. Scientists Korea. 23, 57-73.

18. Karna, E., Nazaruk, J., Szoka, L., and Palka, J. A. (2011) Scutellarin-dependent inhibition of collagen biosynthesis in cultured fibroblasts. Nat. Prod. Res. 25, 1789-1795.

19. Kim, J. K., Lee, J. H., Yang, M. S., Seo, D. B., and Lee, S. J. (2009) Beneficial effect of collagen peptide supplement on anti-aging against photodamage. Korean J. Food Sci. Technol. 41, 441-445.

20. Kim, W. S. (2009) Antiwrinkle effect of adipose-derived stem cell: Activation of dermal fibroblast by secretory factors. J. Dermatol. Sci. 53, 960-102.

21. Lee, J. E. (2010) Epidermal hyperplasia and elevated HB-EGF are more prominent in retinoid dermatitis compared with irritant contact dermatitis induced by benzalkonium chloride. Ann. Dermatol. 22, 290-299.

22. Lee, J. H., Seo, J. H., Park, Y. H., Kim, W. G., Lim, K. M., and Lee, S. J. (2008) The effect of hydroxyproline and prohyp dipeptide on UV-damaged skin of hairless mice. Korean 
J. Food Sci. Technol. 40, 436-442.

23. Matsumoto, H., Ohara, H., Itoh, K., Nakamura, Y., and Takahashi, S. (2006) Clinical effects of fish type I collagen hydrolysate on skin properties. ITE Lett. 7, 386-390.

24. Moskowitz, R. W. (2000) Role of collagen hydrolysate in bone and joint disease. Semin. Arthritis Rheu. 30, 87-99.

25. Oesser, S., Adam, M., Babel, W., and Seifert, J. (1999) Oral administration of ${ }^{14} \mathrm{C}$ labeled gelatin hydrolysate leads to an accumulation of radioactivity in cartilage of mice (C57/BL). J. Nutr. 129, 1891-1895.

26. Ohara, H., Matsumoto, H., Ito, K., Iwai, K., and Sato, K. (2007) Comparison of quantity and structure of hydroxyproline-containing peptides in human blood after oral ingestion of gelatin hydrolysates from different sources. J. Agr. Food Chem. 55, 1532-1535.

27. Oikarinen, A., Karvonen, J., Uitto, J., and Hannuksela, M. (1985) Connective tissue alterations in skin exposed to natural and therapeutic UV-radiation. Photodermatol. 2, 15-26.

28. Park, C. S. (2007) Skin barrier and beauty foods. Food Sci. Indus. 40, 19-26.

29. Park, J. G., Hyun, J. W., Lim, K. H., Shin, J. E., Won, Y. J., and Yi, Y. D. (1993) Antineoplastic effects from traditional medicinal plants. Kor. J. Pharmacogn. 24, 223-230.

30. Park, K. M., Yoo, J. H., and Shin, Y. J. (2012) Effects of egg shell membrane hydrolysates on skin whitening, wound healing, and UV-protection. Korean J. Food Sci. An. 32, 308-315. 31. Rittie, L. and Fisher, G. J. (2002) UV-light-induced sigmal cascades and skin aging. Ageing Res. Rev. 1, 705-720.

32. Saurat, J. H. and Sorg, O. (1999) Topical natural retinoids. The 'pro-ligand-nonligand' concept. Dermatology 199, 1-2.

33. Shin, M. H. (2012) Chronic heat treatment causes skin wrinkle formation and oxidative damage in hairless mice. Mech. Ageing and Development 133, 92-98.

34. Vayalil, P. K., Mittal, A., Hara, Y., Elmets, C. A., and Katiyar, S. K. (2004) Green tea polyphenols prevent UV light-induced oxidative damage and matrix metalloproteinases expression in mouse skin. J. Invest Dermatol. 122, 1480-1487.

35. Vignardet, C. G., Friedrich, Y. C., and Millet, J. (1999) A first order experiment design to assess soluble proteins released by a new keratinase from Doratomyces microsporus on human substrate. Int. J. Pharm. 191, 95-102.

36. Wu, J., Fujioka, M., Sugimoto, K., Mu G., and Ishimi, Y. (2004) Assessment of effectiveness of oral administration of collagen peptide on bone metabolism in growing and mature rats. J. Bone Miner. Metab. 22, 547-553.

37. Yoo, J. H., Park, K. M., Yoo, Y. J., Kim, J. K., Yang, H. J., and Shin, Y. J. (2014) Effects of egg shell membrane hydrolysates on anti-inflammatory, anti-wrinkle, anti-microbial activity and moisture-protection. Korean J. Food Sci. An. 34, 26-32.

38. Yoshinori, T., Yukiko, Y., and Michio, K. (1995) The relationship between age- related changes in the physical properties and development of wrinkles in human facial skin. J. Soc. Cosmet. Scientists Korea 46, 163-173.

(Received 2014.10.27/Revised 2014.11.25/Accepted 2014.11.25) 